\title{
Literature Review: Tinjauan Kesiapan Penerapan Rekam Medis Elektronik Dalam Sistem Informasi Manajemen Di Rumah Sakit
}

\section{Literature Review: Review of Readiness for Application of Electronic Medical Records in Management Information Systems in Hospitals}

\author{
Cordylia Amelinda Jeannette Sulistya ${ }^{1}$, Rohmadi $^{2}$ \\ ${ }^{1,2}$ Prodi D3 RMIK STIKes Mitra Husada Karanganyar \\ Papahan Tasikmadu Karanganyar, 57720 \\ *e-mail korespondensi: Cordyliamelinda7@gmail.com
}

\begin{abstract}
Abstrak
Teknologi informasi dan komunikasi telah berkembang begitu pesat di berbagai sektor, termasuk di sektor kesehatan salah satunya adalah Rekam Medik Elektronik (RME). Penyempurnaan manajemen RME mulai diterapkan di beberapa Rumah Sakit/ Puskesmas di Indonesia. Demikian kompleksnya tantangan untuk implementasi RME, maka perlu dilakukan penilaian kesiapan sebelum implementasi RME. Tujuan penelitian: untuk mengetahui kesiapan penerapan rekam medis elektronik berdasarakan aspek sumber daya manusia, budaya kerja organisasi, tata kelola dan kepemimpinan, dan infrastruktur. Metode penelitian: mengkaji jurnal dengan kriteria yaitu penelitian yang telah dipublikasikan, minimal berasal dari jurnal terakreditasi, dan jurnal yang berkaitan dengan kesiapan penerapan rekam medis elektronik di rumah sakit. Strategi: menggunakan data sekunder yang diperoleh bukan dari pengamatan langsung akan tetapi dari hasil penelitian yang telah dilakukan oleh peneliti terdahulu. Sumber data yang didapat berupa artikel atau jurnal yang relevan dengan topic kesiapan penerapan rekam medis elektronik. Hasil penelitian: kesiapan penerapan rekam medis elektronik masih terdapat beberapa ketidaksiapan dan terdapat juga beberapa yang sudah cukup siap. Berdasarkan aspek sumber daya manusia belum cukup siap, berdasarkan aspek budaya kerja organisasi sudah cukup siap, berdasarkan tata kelola dan kepemimpinan sudah cukup siap, dan berdasarkan infrastruktur belum cukup siap. Saran: perlu adanya perekrutan ahli IT untuk pembuatan software dan untuk mengelola data, diperlukan pembuatan SOP, membentuk tim khusus dan perlu menyediakan perangkat lunak, prosedur, database, jaringan komputer dan komunikasi.
\end{abstract}

Kata kunci : Rekam Medis Elektronik, Kesiapan, Aplikasi, Rumah Sakit

\begin{abstract}
Information and communication technology has developed so rapidly in various sectors, including in the health sector, one of which is Electronic Medical Record (EMR). Improvements in EMR management have begun to be implemented in several hospitals/health centers in Indonesia. As complex as the challenges for RME implementation are, it is necessary to conduct a readiness assessment prior to RME implementation. The purpose: to determine the readiness to apply electronic medical records based on aspects of human resources, organizational work culture, governance and leadership, and infrastructure. Method: using literature review by reviewing journals with criteria, namely research that has been published, at least from accredited journals, and journals related to the readiness to apply electronic medical records in hospitals. Strategy: use secondary data obtained not from direct observation but from the results of research that has been carried out by previous researchers. Sources of data obtained in the form of articles or journals that are relevant to the topic of readiness to apply electronic medical records. The results: the readiness of the application of electronic medical records, there are still some unpreparedness and there are also some who are quite ready. Based on the aspect of human resources, it is not quite ready, based on the organizational culture aspect, it is quite ready,
\end{abstract}

p-ISSN: | e-ISSN: 2807-2596

website: ijhim.stikesmhk.ac.id/index.php/ 
based on governance and leadership, it is quite ready, and based on infrastructure it is not quite ready. Suggestion: it is necessary to recruit IT experts for software development and to manage data, it is necessary to make SOPs, form a special team and provide software, procedures, databases, computer networks and communications.

Keywords: Electronic Medical Record, Readiness, Application, Hospital

\section{PENDAHULUAN}

\begin{abstract}
Rumah sakit wajib meningkatkan kualitas mutu pelayanan kesehatan dengan cara memanfaatkan perkembangan teknologi saat ini agar dapat bersaing dengan baik. Salah satu perkembangan teknologi tersebut adalah Rekam Medis Elektronik (RME). Penggunaan RME merupakan pengaplikasian sebuah teknologi informasi yang digunakan dalam pengumpulan, penyimpanan data, pengolahan data serta pengaksesan data yang tersimpan pada rekam medis pasien di sebuah rumah sakit dalam suatu sistem manajemen basis data yang menghimpun berbagai macam sumber data medis (Handiwidjojo, 2009).
\end{abstract}

Manfaat RME bagi tenaga medis adalah sebagai dasar atau petunjuk untuk merencanakan dan menganalisis sebuah penyakit, merencanakan sebuah pengobatan, perawatan dan tindakan medis yang harus diberikan kepada pasien serta dapat meningkatkan kualitas pelayanan sehingga melindungi tenaga medis untuk mencapai kesehatan masyarakat yang optimal. Namun untuk menerapkan RME dijumpai begitu banyak tantangan yang sedemikian kompleks (Wirajaya, dkk, 2020).

Tantangannya adalah kurangnya definisi seragam akan konsep pengembangan teknologi informasi, kurangnya penilaian kebutuhan sebelum pelaksanaan, adanya kekhawatiran akan terjadinya pelanggaran privasi dan kasus hukum. Tantangan yang lain adalah kurangnya integrasi dan sharing oleh berbagai level manajemen. Penilaian kesiapan akan membantu identifikasi proses dan skala prioritas. Kurangnya kesiapan organisasi adalah penyumbang utama kegagalan RME di industri kesehatan. Beberapa penelitian pada tahun 1999 telah menunjukkan bahwa salah satu faktor yang menyebabkan 50\% institusi kesehatan gagal mengimplementasikan RME adalah karena kurang siapnya rumah sakit dalam mengimplementasikan RME (Snyder-Halpern, 2001).

Teknologi informasi dan komunikasi telah berkembang begitu pesat di berbagai sektor, termasuk di sektor kesehatan salah satunya adalah Rekam Medik Elektronik (RME). Penyempurnaan manajemen RME mulai diterapkan di beberapa Rumah Sakit/ Puskesmas di Indonesia. Demikian kompleksnya tantangan untuk implementasi RME, maka perlu dilakukan penilaian kesiapan sebelum implementasi RME. Ini merupakan langkah yang paling penting untuk dilakukan lebih dahulu sebelum implementasi. Penilaian kesiapan akan membantu identifikasi proses dan skala prioritas, juga membantu pembentukan fungsi operasional untuk mendukung optimalisasi implementasi RME (Ghazisaeidi et al., 2013). Penilaian kesiapan juga merupakan cara untuk mengidentifikasi potensi penyebab kegagalan dalam inovasi (Ajami et al, 2011).

Hasil penelitian (Sudirahayu, dkk, 2016) disebutkan teknologi informasi (TI) memang menawarkan banyak keunggulan dibandingkan dengan penggunaan kertas untuk penyimpanan dan pengambilan data pasien. Namun untuk menerapkan RME dijumpai beberapa tantangan, diantaranya yaitu masalah infrastruktur dan struktur, masalah teknologi informasi, kurangnya need assessment, masalah budaya, tingginya biaya software, hardware, dan standar pertukaran data. Oleh sebab itu perlu dilakukan penilaian kesiapan sebelum implementasi RME. Hal ini akan membantu identifikasi proses dan skala prioritas, juga membantu pembentukan fungsi operasional untuk mendukung optimalisasi implementasi RME. Penilaian kesiapan harus menyeluruh meliputi sumber daya manusia, budaya kerja 
organisasi, tata kelola dan kepemimpinan, dan infrastruktur.

\section{METODE PENELITIAN}

Metode penelitian menggunakan desain literature review. Database yang digunakan yaitu google scholar, kata kunci dan boolean operator yang digunakan dalam penelitian ini yaitu "Rekam medis elektronik" AND "Kesiapan penerapan rekam medis elektronik". Sehingga diperoleh 40 artikel dari google scholar. Kemudian 5 artikel dimasukkan dalam literature review.

\section{HASIL DAN PEMBAHASAN}

\section{HASIL}

Tabel 1. Hasil Ekstrasi Data

\begin{tabular}{|c|c|c|}
\hline $\begin{array}{c}\text { Penulis } \\
\text { (Tahun) }\end{array}$ & Judul & Hasil \\
\hline $\begin{array}{l}\text { Ika } \\
\text { Sudiraha } \\
\text { yu dan } \\
\text { Agus } \\
\text { Harjoko } \\
(2016)\end{array}$ & $\begin{array}{l}\text { Analisis } \\
\text { Kesiapan } \\
\text { Penerapan } \\
\text { Rekam } \\
\text { Medis } \\
\text { Elektronik } \\
\text { Menggunaka } \\
\text { n DOQ-IT di } \\
\text { RSUD Dr. } \\
\text { H. Abdul } \\
\text { Moeloek } \\
\text { Lampung }\end{array}$ & $\begin{array}{l}\text { 1. Sumber daya manusia: } \\
\text { sebagian besar }(45,16 \%) \\
\text { pengguna berpendidikan } \\
\text { S1 sederajat, namun } \\
\text { sumber daya manusia yang } \\
\text { memiliki kemampuan } \\
\text { spesifik dibidang teknologi } \\
\text { informasi belum } \\
\text { mencukupi untuk } \\
\text { mengelola seluruh proses } \\
\text { pengolahan data dan } \\
\text { maintenance infrastruktur } \\
\text { teknologi informasi secara } \\
\text { mandiri. } \\
\text { 2. Budaya kerja organisasi: } \\
\text { kesiapan budaya } \\
\text { mencakup penerimaan } \\
\text { tenaga kesehatan atas } \\
\text { teknologi informasi } \\
\text { diperlukan peningkatan } \\
\text { pengetahuan dan } \\
\text { kesadaran pengguna akan } \\
\text { pentingnya rekam medis. } \\
\text { Tenaga kesehatan harus } \\
\text { memiliki pemahaman dan } \\
\text { komitmen untuk } \\
\text { pelaksanaan sesuai yang } \\
\text { direncanakan. Memotivasi } \\
\text { praktisi kesehatan untuk } \\
\text { berkomitmen } \\
\text { melaksanakan proses } \\
\text { sesuai dengan perubahan }\end{array}$ \\
\hline
\end{tabular}

alur kerja. Menangani tantangan dan hambatan, dan menerima saran dan modifikasi berdasarkan masukan 3.Tata kelola dan kepemimpinan: pimpinan di RSUD Dr. H. Abdul Moeloek berkomitmen terhadap penerapan RME. Ini dibuktikan dengan telah dibentuknya instalasi yang bertanggungjawab menangani SIMRS, yaitu instalasi EDP-TI. Ini sesuai dengan konsep pengembangan sistem informasi manajemen yang menyebutkan harus ada bagian khusus yang mengelola sistem informasi untuk penerapan RME sebagai bukti komitmen manajemen 4. Infrastruktur: aplikasi SIMRS di RSUD Dr. H. Abdul Moeloek menggunakan server dengan kapasitas sementara 8 Terabytes, dan kapasitas ini sifatnya dinamik, kalau dirasa kurang bisa ditambahkan lagi. Database yang digunakan adalah SyBase dan bahasa pemrograman Power Builder. Sedangkan untuk hardware ada 176 Personal Computer khusus untuk SIMRS yang ditempatkan disetiap ruangan yang sudah ditentukan dengan spesifikasi memadai.

\begin{tabular}{lll}
\hline Anas & Analisis & 1. Sumber daya manusia: \\
Rahmat & Kesiapan & memberikan pelayanan \\
Hidayat & (Readiness & pasien secara manual. \\
dan & Assessment) & 2. Budaya kerja organisasi: \\
Ersihana & Penerapan & belum ada kebijakan \\
Wulan & Electronic & terkait pengembanagan \\
Sari & Medical & sistem electronic medical \\
$(2017)$ & Record di & record. Belum ada \\
& Klinik & pengajuan rencana \\
& Rawat Inap & implementasi sistem \\
\hline
\end{tabular}




\begin{tabular}{|c|c|c|}
\hline & $\begin{array}{l}\text { Pku } \\
\text { Muhammadi } \\
\text { yah Pakem }\end{array}$ & $\begin{array}{l}\text { electronic ke pimpinan } \\
\text { cabang Muhammadiyah } \\
\text { Pakem. } \\
\text { 3. Tata kelola dan } \\
\text { kepemimpinan: pada jurnal } \\
\text { ini tidak membahas } \\
\text { tentang tata kelola dan } \\
\text { kepemimpinan. } \\
\text { 4. Infrastruktur: hardware } \\
\text { (komputer, CPU, printer) } \\
3 \text { buah, jaringan telepon } 1 \\
\text { buah. }\end{array}$ \\
\hline $\begin{array}{l}\text { Muham } \\
\text { mad } \\
\text { Hamdani } \\
\text { Pratama } \\
\text { dan Sri } \\
\text { Darnoto } \\
(2017)\end{array}$ & $\begin{array}{l}\text { Analisis } \\
\text { Strategi } \\
\text { Pengembang } \\
\text { an Rekam } \\
\text { Medis } \\
\text { Elektronik } \\
\text { di Instalasi } \\
\text { Rawat Jalan } \\
\text { RSUDKota } \\
\text { Yogyakarta }\end{array}$ & $\begin{array}{l}\text { 1. Sumber daya manusia: } \\
\text { memiliki staf TI sebanyak } \\
6 \text { orang untuk mendukung } \\
\text { berjalannya kegiatan } \\
\text { teknologi informasi } \\
\text { termasuk dalam } \\
\text { pemeliharaan SIMRS. } \\
\text { 2. Budaya kerja organisasi: } \\
\text { alur kerja rekam medis } \\
\text { elektronik belum } \\
\text { terencana. } \\
\text { 3. Tata kelola dan } \\
\text { kepemimpinan: tim khusus } \\
\text { tersebut saat ini belum ada } \\
\text { di RSUD Kota Yogyakarta } \\
\text { sehingga untuk proses } \\
\text { pengembangan ke depan } \\
\text { diperlukan pembentukan } \\
\text { tim eksekutif dalam } \\
\text { perencanaan sistem } \\
\text { informasi rumah sakit. } \\
\text { 4. Infrastruktur: adanya } \\
\text { teknologi RME dipandang } \\
\text { sebagai sebuah investasi, } \\
\text { namun proses perencanaan } \\
\text { anggaran secara khusus } \\
\text { belum diidentifikasi secara } \\
\text { terperinci untuk proses } \\
\text { pengembangan RME. }\end{array}$ \\
\hline Made & Analisis & 1.Sumber daya manusia: \\
\hline Karma & Kesiapan & Rumah Sakit Dharma Kerti \\
\hline Maha & Rumah Sakit & Tabanan cukup siap dalam \\
\hline Wirajaya & Dharma & menerapkan RME. Hal ini \\
\hline dan $\mathrm{Ni}$ & Kerti & diperkuat dengan hasil \\
\hline Made & Tabanan & wawancara kepada \\
\hline Umi & Menerapkan & informasi yakni secara \\
\hline Kartika & Rekam & keseluruhan rumah sakit \\
\hline Dewi & Medis & ini memiliki beberapa hal \\
\hline$(2020)$ & Elektronik & $\begin{array}{l}\text { yang sudah dipenuhi untuk } \\
\text { menerapkan rekam medis } \\
\text { elektronik tetapi juga } \\
\text { masih ada beberapa }\end{array}$ \\
\hline
\end{tabular}

\begin{tabular}{|c|c|c|}
\hline & & $\begin{array}{l}\text { kekurangan yang perlu } \\
\text { dipenuhi. } \\
\text { 2. Budaya kerja organisasi: } \\
\text { rumah sakit ini cukup } \\
\text { mampu untuk menerapkan } \\
\text { rekam medis elektronik } \\
\text { karena sudah memiliki } \\
\text { sistem informasi rumah } \\
\text { sakit yang telah berjalan } \\
\text { dengan baik dan juga } \\
\text { lingkup rumah sakit ini } \\
\text { tidak terlalu kompleks } \\
\text { sehingga penerapan rekam } \\
\text { medis elektronik bisa lebih } \\
\text { cepat. } \\
\text { 3.Tata kelola dan } \\
\text { kepemimpinan: pemimpin } \\
\text { belum membentuk suatu } \\
\text { tim khusus dalam rangka } \\
\text { mempercepat penerapan } \\
\text { rekam medis elektronik } \\
\text { namun komitmen } \\
\text { pemimpin untuk } \\
\text { menggunakan rekam } \\
\text { medis elektronik sudah } \\
\text { ada. } \\
\text { 4. Infrastruktur: rumah } \\
\text { sakit ini memiliki fasilitas } \\
\text { IT yang memadai hanya } \\
\text { saja belum memiliki IT } \\
\text { untuk mendukung } \\
\text { penerpan rekam medis } \\
\text { elektronik. }\end{array}$ \\
\hline $\begin{array}{l}\text { Eka } \\
\text { Wilda } \\
\text { Faida } \\
\text { dan Amir } \\
\text { Ali } \\
(2021)\end{array}$ & $\begin{array}{l}\text { Analisis } \\
\text { Kesiapan } \\
\text { Implementas } \\
\text { i Rekam } \\
\text { Medis } \\
\text { Elektronik } \\
\text { dengan } \\
\text { Pendekatan } \\
\text { DOQ-IT } \\
\text { (Doctor's } \\
\text { Office } \\
\text { Quality- } \\
\text { Information } \\
\text { Technology) }\end{array}$ & $\begin{array}{l}\text { 1. Sumber daya manusia: } \\
\text { sebagian besar petugas } \\
\text { telah menunjukkan } \\
\text { kesiapannya dalam } \\
\text { implementasi RME. } \\
\text { Namun masih ada } \\
\text { beberapa petugas yang } \\
\text { menyatakan belum siap, } \\
\text { salah satunya didominasi } \\
\text { pada pernyataan } \\
\text { ketidakmauan menjalankan } \\
\text { RME. } \\
\text { 2. Budaya kerja organisasi: } \\
\text { ketidaktersediaan petunjuk } \\
\text { menjalankan rekam medis } \\
\text { elektronik sebesar } 14 \% \\
\text { dan tidak ada pelibatan } \\
\text { petugas dalam } \\
\text { perencanaan rekam medis } \\
\text { elektronik sebesar } 10 \% \text {. } \\
\text { 3.Tata kelola dan }\end{array}$ \\
\hline
\end{tabular}


kepemimpinan:

ketidaktersediaan regulasi

tentang himbauan

menjalankan rekam medis

elektronik sebesar $16 \%$.

4. Infrastruktur:

ketersediaan server dan

komputer belum

memadahi dalam

menjalankan rekam medis

elektronik sebesar $48 \%$

dan menu aplikasi rekam

medis elektronik yang

tersedia kurang dapat

memenuhi kebutuhan

petugas menjalankan

rekam medis elektronik

sebesar $26 \%$.

Hasil Sintesis

Sintesis dalam penelitian ini menggunakan tema:

a. Kesiapan penerapan rekam medis elektronik berdasarkan aspek sumber daya manusia

b. Kesiapan penerapan rekam medis elektronik berdasarkan aspek budaya kerja organisasi

c. Kesiapan penerapan rekam medis elektronik berdasarkan aspek tata kelola dan kepemimpinan

d. Kesiapan penerapan rekam medis elektronik berdasarkan aspek infrastruktur

\section{PEMBAHASAN}

\section{Kesiapan Penerapan Rekam Medis Elektronik Berdasarkan Aspek Sumber Daya Manusia}

Pada penelitian (Sudirahayu, dkk, 2016) ditemukan sebagian besar $(45,16 \%)$ pengguna berpendidikan $\mathrm{S} 1$ sederajat, namun sumber daya manusia yang memiliki kemampuan spesifik dibidang teknologi informasi belum mencukupi untuk mengelola seluruh proses pengolahan data dan maintenance infrastruktur teknologi informasi secara mandiri. Sejalan dengan penelitian (Hidayat, dkk, 2017) saat ini belum ada ahli IT sebagai pembuat program (software) sekaligus sebagai penanggung jawab dalam pengembangan sistem electronic medical record. Hal ini belum sesuai dengan Peraturan Menteri Kesehatan Republik Indonesia Nomor 82 tahun 2013 tentang Sistem Informasi Manajen Rumah Sakit menyebutkan bahwa Sumber daya manusia teknologi informasi untuk SIMRS minimal terdiri dari staf yang memiliki kualifikasi dalam bidang analisis sistem, programmer, hardware dan maintanance jaringan (Kemenkes, 2013). Berbeda dengan peneltian (Pratama, dkk, 2017), (Wirajaya, dkk, 2020) dan (Faida, dkk, 2021) yang sudah terdapat sumber daya manusia dalam menjalankan rekam medis elektronik.

Sehingga, dapat disimpulkan bahwa kesiapan penerapan rekam medis elektronik pada aspek sumber daya manusia masih belum cukup siap. SDM adalah faktor strategis dalam kegiatan yang membuat sumber daya yang lain dapat bekerja dengan baik dan mampu mencapai tujuan secara efektif dan efisien (Simamora, 2006). Hal tersebut menunjukkan bahwa perencanaan terhadap SDM di sebuah organisasi harus terdokumentasi dengan baik dan diusulkan pada bagian personalia di rumah sakit. Kemampuan staf atau pegawai untuk mengoperasikan sebuah komputer juga menjadi salah satu komponen penting yang mendukung pengembangan dan percepatan penerapan RME.

\section{Kesiapan Penerapan Rekam Medis Elektronik Berdasarkan Aspek Budaya Kerja Organisasi}

Pada penelitian (Wirajaya, dkk, 2020)

Rumah Sakit Dharma Kerti Tabanan berada pada kondisi cukup siap yakni sudah memiliki sistem informasi yang telah berjalan dengan baik dan juga lingkup rumah sakit ini tidak terlalu kompleks namun masih ada beberapa komponen yang kurang yaitu belum adanya gambaran sistem rekam medis elektronik yang akan berjalan dan juga belum adanya SOP terkait hal tersebut. Sejalan dengan (Pratama, 2016) yakni kesiapan dari segi budaya organisasi di RSUD Yogyakarta adalah cukup siap dan juga memiliki kekurangan yang sama yakni alur kerja rekam medis elektronik yang belum terencana. Hal ini berbeda dengan penelitian (Hidayat, dkk, 2017) yang belum adanya kebijakan terkait pengembangan RME dan belum adanya pengajuan rencana implementasi sistem RME ke pimpinan cabang Muhammadiyah Pakem.

Dapat disimpulkan bahwa kesiapan penerapan rekam medis elektronik pada budaya kerja organisasi sudah cukup siap. Diperlukan 
promosi aspek budaya kerja di berbagai kelompok pemangku kepentingan, meningkatkan kondisi kerjasama dalam pelaksanaannya, menciptakan proses manajerial yang tepat, penyediaan infrastruktur dan pemberian orientasi dan pelatihan sesuai kebutuhan kelompok pengguna (Ghazisaeldi et al, 2013).

\section{Kesiapan Penerapan Rekam Medis Elektronik Berdasarkan Aspek Tata Kelola dan Kepemimpinan}

Kepemimpinan dan tata kelola merupakan salah satu komponen yang berpengaruh signifikan terhadap percepatan penerapan rekam medis elektronik. Kepemimpinan pada dasarnya adalah kemampuan seseorang dalam mempengaruhi karyawannya untuk mencapai sebuah tujuan yang telah ditetapkan bersama (Robbins, 2006). Pemimpin memliki peran yang sangat penting terutama dalam hal pengambilan keputusan. Pada penelitian (Wirajaya, dkk, 2020) berada pada kondisi cukup siap yakni pemimpin sudah ada wacana dalam menjalankan RME dan juga sudah memiliki sistem informasi yang terkomputerisasi namun masih ada yang kurang yakni belum terbentuknya tim khusus untuk mempercepat rekam medis elektronik dan juga belum adanya strategi dalammempercepat penerapan rekam medis elektronik. Hasil penelitian ini sejalan dengan penelitian (Sudirahayu, dkk, 2016) bahwa pemimpin memiliki komitmen dalam menerapkan RME di sebuah rumah sakit dan juga belum memiliki strategi dalam mempercepat penerapan rekam medis elektronik.

Dapat disimpulkan bahwa kesiapan penerapan rekam medis elektronik pada aspek tata kelola dan kepemimpinan sudah cukup siap, seperti pemimpin yang sudah memiliki wacana dalam menerapkan RME, tetapi masih belum terbentuknya tim khusus untuk mempercepat penerapan RME.

\section{Kesiapan Penerapan Rekam Medis Elektronik Berdasarkan Aspek Infrastruktur}

Adopsi EHR secara menyeluruh memerlukan biaya yang banyak dan memerlukan proses yang panjang (Carroll et all, 2012). Untuk itu diperlukan adanya kesiapan dari sisi infrastruktur TI maupun anggarannya. Pada penelitian (Hidayat, dkk, 2017) belum memiliki software (perangkat lunak), prosedur, database, jaringan komputer dan komunikasi. Sejalan dengan penelitian (Faida, dkk, 2021) ketersediaan server dan komputer belum memadahi dalam menjalankan rekam medis elektronik sebesar $48 \%$ dan menu aplikasi rekam medis elektronik yang tersedia kurang dapat memenuhi kebutuhan petugas menjalankan rekam medis elektronik sebesar 26\%. Hal ini belum sesuai dengan teori yang menyatakan bahwa untuk mendukung inovasi SI yang akan dibangun, misalnya SIMRS, diperlukan kesiapan teknis yakni kemampuan dari hardware dan software (Synder, 2021).

Dapat disimpulkan bahwa masih kurangnya kesiapan penerapan rekam medis elektronik pada aspek infrastruktur TI seperti belum tersedianya software dan komputer yang belum memadai. Selain bergantung pada SDM, suatu SI bergantung pada hardware, software, database, serta jaringan untuk melakukan input, pemrosesan, output, penyimpanan dan aktifitas pengendalian yang mengubah sumber daya data menjadi produk informasi (Oktri, 2011).

\section{SIMPULAN}

Kesiapan penerapan rekam medis elektronik berdasarkan aspek sumber daya manusia sebagian besar belum cukup siap karena saat ini belum ada ahli IT sebagai pembuat program (software) sekaligus sebagai penanggung jawab dalam pengembangan sistem electronic medical record. Kesiapan penerapan rekam medis elektronik berdasarkan aspek budaya kerja organisasi dinyatakan sudah cukup siap, tetapi sebagian besar belum adanya SOP dan alur kerja rekam medis elektronik yang belum terencana. Kesiapan penerapan rekam medis elektronik berdasarkan aspek tata kelola dan kepemimpinan sudah cukup siap seperti pemimpin yang sudah memiliki wacana dalam menerapkan RME, tetapi masih belum terbentuknya tim khusus untuk mempercepat penerapan RME. Kesiapan penerapan rekam medis elektronik berdasarkan aspek infrastruktur sebagian belum cukup siap seperti belum tersedianya software dan komputer yang belum memadai. 


\section{DAFTAR PUSTAKA}

Ajami S, Ketabi S, Isfahani SS, Heidari A. Readiness assessment of electronic health records implementation. Acta Inform Med. $2011 ; 19$

(4):224-227. doi:10.5455/aim.2011.19.224-227

Faida, E. W. \& Ali, A. (2021). Analisis Kesiapan Implementasi Rekam Medis Elektronik dengan Pendekatan DOQ-IT (Doctor's Office Quality-Information Technology). Diakses pada tanggal 30 Maret 2021.https://jmiki.aptirmik.or.id/index.php/j $\underline{\text { miki/article/view/315 }}$

Ghazisaeldi, M., Maryam Ahmadi., Farahnaz Sadought dan Reza Safdari. (2013). An Assessment of Readiness for PreImplementation of Electronic Health Record in Iran: a practical Approachto Implementation in general and Teaching Hospital. Retrieved from http://acta.tums.ac.ir/index.php/acta/article/ download/4579/4509.pdf

Handiwidjojo, W. (2009). Rekam Medis Elektronik. Diambil dari http://ti.ukdw.ac.id/ojs/index. php/eksis/article/download/383/163.pdf pada 10 April 2016

Hidayat, A. R. \& Sari, E. W. (2017). Analisis Kesiapan (Readiness Assessment) Penerapan Electronic Medical Record di Klinik Rawat Inap Pku Muhammadiyah Pakem. Diakses pada tanggal 2 Februari 2021.

http://ejournal.ijmsbm.org/index.php/ijms/a rticle/view/106/0

Kemenkes RI. Peraturan Menteri Kesehatan RINO. 82 Tahun 2013 Tentang Sistem Informasi Manajemen Rumah Sakit. Indonesia; 2013.

Oktri, dkk. (2011). Analisis Faktor-Faktor yang Mempengaruhi Proses Migrasi dari Medical Record ke Electronic Medical Record di Rumah Sakit, Bandung: S2 Teknik Industri Universitas Widyatama Bandung.
Pratama, M. H. \& Darnoto, S. (2017). Analisis Strategi Pengembangan Rekam Medis Elektronik di Instalasi Rawat Jalan RSUD Kota Yogyakarta. Diakses pada tanggal 2 Februari 2021. https://jmiki.aptirmik.or.id/index.php/jmiki/ article/view/146

Robbins, S. P. (2006). Perilaku Organisasi $\left(10^{\text {th }}\right.$ ed.). Jakarta: Indeks.

Silow-Carroll, S., Edwards, J. N., \& Rodin, D. (2012). Using electronic health records to improve quality and efficiency: the experiences of leading hospitals. Issue Brief (Commonwealth Fund), 17, 1-40.Retrieved from

http://www.ncbi.nlm.nih.gov/pubmed/2282 $\underline{690}$

Simamora, H. (2004). Manajemen Sumber Daya Manusia ( $3^{\text {rd }}$ ed.). STIE YKPN Yogyakarta.

Snyder-Halpern, R. (2001). Indicators of organizational readiness for clinical information technology/systems innovation: a Delphi study. International Journal of Medical Informatics, 63(3), 179-204. https://doi.org/10.1016/S1386$\underline{5056(01) 00179-4}$

Sudirahayu, I. \& Harjoko, A. (2016). Analisis Kesiapan Penerapan Rekam Medis Elektronik Menggunakan DOQ-IT di RSUD Dr. H. Abdul Moeloek Lampung. Diakses pada tanggal 30 Januari 2021. https://www.neliti.com/id/publications/196 280/analisis-kesiapan-penerapan-rekammedis-elektronik-menggunakan-doq-it-di$\underline{\text { rsud-dr }}$

Wirajaya, M. K. M. \& Dewi, N. M. U. K. (2020). Analisis Kesiapan Rumah Sakit Dharma Kerti Tabanan Menerapkan Rekam Medis Elektronik. Diakses pada tanggal 3 Maret 2021.

https://jurnal.ugm.ac.id/jkesvo/article/view/ 53017 